\title{
Identificação molecular de isolados de fungos de interesse médico por meio de marcadores RAPD
}

\author{
Anabele Azevedo Lima' \\ Valdi Lopes Tutunji ${ }^{2}$ \\ Luzia Helena Corrêa Lima ${ }^{3}$ \\ Paulo Roberto Queiroz ${ }^{4}$
}

\section{Resumo}

Aspergillus e Penicillium são microrganismos capazes de provocar complicações clínicas consideráveis, principalmente em pacientes imunossuprimidos. A análise molecular é uma estratégia importante para a identificação rápida e precisa desses agentes patogênicos. Por isso, o objetivo deste trabalho é descrever padrões de marcadores RAPD específicos para a identificação de isolados de Aspergillus e Penicillium causadores de doenças de interesse médico. A análise morfológica revelou que 14 isolados eram do gênero Aspergillus, 7 eram Penicillium, 1 correspondente a Fusarium e 1 isolado não foi identificado. A análise por RAPD com 10(dez) iniciadores produziu fragmentos de DNA característicos para cada gênero. O dendrograma revelou grupos de isolados dentro de cada gênero de fungo de acordo com perfis de marcadores específicos, identificando isolados muito semelhantes que apresentaram alto coeficiente de similaridade. Esses dados fornecem opções para o desenvolvimento de oligonucleotídios de PCR para a identificação de isolados específicos que ocorrem no ambiente médico-hospitalar.

Palavras-chave: Análise de DNA. Aspergillus. Penicillium. Polimorfismo.

1 Graduada em Biologia. UniCEUB. Mestre em Biologia Molecular - UnB; e-mail: anabelebio@gmail.com

2 Especialista em Saúde Pública - Fundação Oswaldo Cruz; e-mail: antibios@antibios.org

3 Ph. D Biologia Molecular. Embrapa Recursos Genéticos e Biotecnologia. e-mail: luzia@ cenargen.embrapa.br

4 Ph. D Biologia Animal. Universidade de Brasília - UnB. Professor do curso de Biomedicina UniCEUB; e-mail: pqsilva@uol.com.br.

Apoio: Projeto Institucional Vinculado ao UniCEUB 


\section{Introdução}

O Filo Ascomycota possui 46 ordens e cerca de 6.000 gêneros, entre eles encontram-se os gêneros Aspergillus, Penicillium e Fusarium. As espécies do gênero Aspergillus caracterizam-se por apresentarem conidióforos simples, com parede celular lisa, verrugosa, hialinos ou pigmentados. São agentes oportunistas por excelência, pois podem provocar colonização em cavidades preexistentes, infecção, processos alérgicos e intoxicações (DIAZ-GUERRA, 2000; MELLADO, 2000).

Os membros do gênero Aspergillus spp, por serem patógenos oportunistas, causam a maioria das infecções ocorridas em pessoas imunodeprimidas. Aspergillus fumigatus é um dos agentes mais comuns que causam infecções sistêmicas, seguido da espécie Aspergillus flavus. São fungos filamentosos que podem causar aspergilose bronquiopulmonar, aspergiloma e aspergilose invasiva. Tais condições são geralmente adquiridas pela inalação dos conidiósporos do fungo, causando infecções pulmonares ou pela ingestão de alimentos contaminados (RHAME, 1991).

A maioria das espécies do gênero Penicillium é saprófita, sendo encontradas no solo, em vegetais em decomposição, em sementes e em grãos (PITT, 1994). Várias espécies são conhecidas pela importância na produção de uma variedade de metabólitos secundários bioativos de importância farmacológica. Entretanto, algumas espécies são capazes de provocar doenças oportunistas em humanos, tais como, infecções no sistema nervoso central em pacientes imunossuprimidos (NORITOMI et al, 2005). A taxonomia e classificação são feitas por meio de critérios morfológicos e bioquímicos (LARSEN, 2000).

As espécies do gênero Fusarium possuem uma classificação baseada em características morfológicas, pigmentação, taxa de crescimento, especificidade de hospedeiros e perfil de metabólitos secundários (THRANE, 1990). Em função das variações nas características fenotípicas, a taxonomia do gênero Fusarium, baseada somente em conceitos morfológicos, não é totalmente satisfatória (OLIVEIRA, 2002). As espécies de Fusarium são patógenos oportunistas que causam micoses que podem ser fatais (HUE; HUERRE; ROUFFAUT, 1999). 
Sendo assim, a análise molecular é uma ferramenta importante no estabelecimento de um sistema complementar de identificação de fungos. Estudos recentes vêm aplicando técnicas moleculares como a análise do polimorfismo do DNA amplificado ao acaso (RAPD) (WILLIAMS ., 1990) o qual tem demonstrado ser um método rápido na identificação de espécies, tais como: A. fumigatus, Aspergillus terreus, Fusarium oxysporum, Fusarium sporotrichioides e Penicillium expansum (LEENDERS et al, 1996; HUE, 1999; RATH, 1999; SYMOENS, 2000; WILSON, 2004; LOURENÇO, 2007).

Os marcadores RAPD podem auxiliar na identificação de microrganismos por meio de suas diferenças genéticas, como também identificar e agrupar genótipos diferentes de várias espécies. Além disso, são procedimentos que ampliam o conhecimento da diversidade genética, contribuindo com mais um parâmetro no controle de qualidade de ambientes hospitalares e identificação de patógenos oportunistas (BERED, 1997). Ressalte-se também que, a partir de marcadores RAPD específicos para cada gênero de fungo, é possível a conversão para marcadores baseados em PCR, aumentando a precisão, a eficiência e a rapidez do processo de identificação de fungos causadores de doenças de importância médica.

\section{Objetivo}

Descrever padrões de marcadores RAPD específicos para a identificação de isolados de Aspergillus, Fusarium e Penicillium causadores de doenças de interesse médico.

\section{Materiais e métodos}

\section{Isolados de fungos}

Foram analisados 23 isolados de Aspergillus, Fusarium e Penicillium (Tabela 1) previamente identificados e pertencentes à coleção de fungos do curso de biomedicina do Centro Universitário de Brasília (UniCEUB). 


\section{Crescimento dos isolados de fungos}

Isolados de Aspergillus, Fusarium e Penicillium foram crescidos previamente em frascos de vidro de $100 \mathrm{~mL}$ contendo $10 \mathrm{~mL}$ de meio BDA (Dextrose $40 \mathrm{~g}$. $\mathrm{L}^{-1}$; Ágar 30 g. L ${ }^{-1}$; Infusão de batata q. s. p. $1000 \mathrm{~mL}$ ) a $25^{\circ} \mathrm{C}$ por $72 \mathrm{~h}$.

Após a esporulação, esporos foram transferidos para frascos de vidro de 100 $\mathrm{mL}$ contendo $20 \mathrm{~mL}$ de meio BDA e incubados a $25^{\circ} \mathrm{C}$ por $72 \mathrm{~h}$.

Em seguida, adicionou-se a cada frasco cerca de $40 \mathrm{~mL}$ de meio YG (Extrato de levedura 5 g. L ${ }^{-1}$; Glicose 20 g. L ${ }^{-1}$; Água destilada q. s. p. 1000 mL), mantendo-se a 25 ${ }^{\circ} \mathrm{C}$ por 5 dias, até obter uma quantidade de micélio suficiente para a extração do DNA.

\section{Extração de DNA}

Para se obter DNA genômico, utilizou-se uma adaptação da metodologia descrita por Azevedo . (2003). Após o crescimento dos fungos em meio YG, os micélios foram filtrados em papel de filtro $(12,3 \mathrm{~cm}$ de diâmetro), lavados duas vezes com $200 \mathrm{~mL}$ de água destilada, identificados e armazenados a $-20{ }^{\circ} \mathrm{C}$ até o momento do uso.

Com o auxílio de um bisturi, foram retirados aproximadamente $200 \mathrm{mg}$ de massa micelial e transferidos para um tubo plástico de 1,5 $\mathrm{mL}$ onde foram macerados manualmente.

Após a maceração, adicionou-se à amostra $500 \mu \mathrm{L}$ da solução de extração de DNA (50 mL de sacarose $2 \mathrm{M}, 0,2 \mathrm{~mL}$ de $\beta$-mercaptoetanol (100\%), NaCl 100 $\mathrm{mM}$ e SDS 0,5\% e água destilada q. s. p. $200 \mathrm{~mL}$ ). Em seguida, adicionou-se 500 $\mu \mathrm{L}$ da solução fenol/clorofórmio/álcool isoamílico (25:24: 1) em cada tubo plástico, agitando-se em vortex por 45s e armazenando-se os tubos no gelo por $5 \mathrm{~min}$. Repetiu-se a agitação e submeteram-se os tubos à centrifugação de $13.000 \mathrm{x} g$ por $10 \mathrm{~min}$. O sobrenadante foi transferido para novos tubos plásticos de $1,5 \mathrm{~mL}$, no qual foi acrescentado novamente $500 \mu \mathrm{L}$ da solução fenol/clorofórmio/álcool isoamílico, seguindo-se agitação e centrifugação a $13.000 \mathrm{x} g$ por 10 minutos. 
Tabela 1: Isolados de fungos utilizados na obtenção dos marcadores moleculares RAPD.

\begin{tabular}{ccc}
\hline Número da amostra & Código do isolado & Gênero \\
\hline 1 & F117 & Aspergillus sp. \\
\hline 2 & F123 & Não identificado \\
3 & F0099 & Penicillium sp. \\
4 & F132 & Aspergillus sp. \\
5 & F004 & Aspergillus sp. \\
6 & F013 & Penicillium $\mathrm{sp}$. \\
7 & F121 & Aspergillus sp. \\
8 & F0065 & Penicillium $\mathrm{sp}$. \\
9 & $\mathrm{~F} 135$ & Aspergillus $\mathrm{sp}$. \\
10 & $\mathrm{P} 002$ & Fusarium $\mathrm{sp}$. \\
11 & $\mathrm{~F} 076$ & Aspergillus $\mathrm{sp}$. \\
12 & $\mathrm{~F} 024$ & Aspergillus $\mathrm{sp}$. \\
13 & $\mathrm{~F} 136$ & Aspergillus $\mathrm{sp}$. \\
14 & $\mathrm{~F} 133$ & Aspergillus $\mathrm{sp}$. \\
15 & $\mathrm{~F} 118$ & Aspergillus $\mathrm{sp}$. \\
16 & $\mathrm{~F} 0062$ & Penicillium $\mathrm{sp}$. \\
17 & $\mathrm{~F} 0002$ & Aspergillus $\mathrm{sp}$. \\
18 & $\mathrm{~F} 122$ & Aspergillus $\mathrm{sp}$. \\
19 & $\mathrm{~F} 0125$ & Aspergillus $\mathrm{sp}$. \\
20 & $\mathrm{~F} 0012$ & Penicillium $\mathrm{sp}$. \\
21 & $\mathrm{~F} 0129$ & Penicillium $\mathrm{sp}$. \\
22 & $\mathrm{~F} 134$ & Aspergillus $\mathrm{sp}$. \\
23 & $\mathrm{~F} 119$ & Aspergillus $\mathrm{sp}$. \\
\hline
\end{tabular}

O sobrenadante foi transferido para novos tubos plásticos de $1,5 \mathrm{~mL}$, sendo ajustada a concentração de $\mathrm{NaCl}$ do sobrenadante para 0,3 M. Em seguida, foram adicionados dois volumes de etanol $100 \%$ gelado $\left(4^{\circ} \mathrm{C}\right)$, incubando-se os tubos por $16 \mathrm{~h} \mathrm{a}-20^{\circ} \mathrm{C}$.

Após a precipitação, as amostras foram centrifugadas a $13.000 \times \mathrm{x}$ por 5 min. O etanol foi descartado e adicionado $500 \mu \mathrm{L}$ de etanol $70 \%$ gelado, centrifugando-se a $13.000 \mathrm{x} g$ por $5 \mathrm{~min}$. Em seguida, o etanol foi descartado, o processo repetido e os precipitados de ácidos nucléicos foram secos à temperatura ambiente.

Posteriormente os ácidos nucleicos totais foram ressuspensos em $200 \mu \mathrm{L}$ de TE 1 X (Tris-HCl 10 mM pH 8,0 e EDTA 1 mM pH 8. 0). Adicionou-se $1 \mu \mathrm{L}$ 
de RNase $\mathrm{A}\left(20 \mathrm{mg}\right.$. $\left.\mathrm{mL}^{-1}\right)$ às amostras, mantendo-se a $37^{\circ} \mathrm{C}$ por $2 \mathrm{~h}$. Ao final, as amostras foram mantidas a $10^{\circ} \mathrm{C}$ ou a $-20^{\circ} \mathrm{C}$ até o momento do uso. Para as análises por RAPD, as amostras de DNA foram diluídas para $20 \mathrm{ng}$. $\mu \mathrm{L}^{-1}$ com TE $0,1 \mathrm{X}$ (Tris-HCl $1 \mathrm{mM} \mathrm{pH} \mathrm{8,0} \mathrm{e} \mathrm{EDTA} \mathrm{0,1} \mathrm{mM} \mathrm{pH} \mathrm{8.} \mathrm{0).}$

\section{Reações de RAPD}

As reações de amplificação foram feitas em um volume total de $35 \mu \mathrm{L}$, contendo 24,9 $\mu \mathrm{L}$ de água milliQ, 3,0 $\mu \mathrm{L}$ de tampão $10 \mathrm{X}$ (Amersham Biotech), 0,6 $\mu \mathrm{L}$ de dNTP's $10 \mathrm{mM}$ (Invitrogen), 1,2 $\mu \mathrm{L}$ iniciador (Operon Technologies, CA, USA) na concentração de $10 \mu \mathrm{M}, 0,3 \mathrm{U} \cdot \mu \mathrm{L}^{-1}$ Taq DNA polimerase (Invitrogen) e $5 \mu \mathrm{L}$ do DNA (20 ng. $\left.\mu \mathrm{L}^{-1}\right)$.

Foram utilizados vinte iniciadores de sequência aleatória (OPA-03: AGTCAGCCAC; OPA-04: AATCGGGCTG; OPA-10: GTGATCCGAG; OPA-11: CAATCGCCGT; OPA-12: TCGGCGATAG; OPA-13: CAGCACCCAC; OPA-15: TTCCGAACCC; OPA-17: GACCGCTTGT; OPA-18: AGGTGACCGT; OPA-20: GTTGGTGGCT; POR-01: TGCGGGTCCT; OPR-02: CACAGCTGCC; OPR-04: CCCGTAGCAC; OPR-05: GACCTAGTGG; OPR-06: GTCTACGGCA; OPR-08: CCCGTTGCCT; OPR-09: TGAGCACGAG; OPR-10: CCATTCCCCA; OPR13: GGACGACAAG; OPR-14: CAGGATTCCC) para a obtenção dos perfis de RAPD. Ao final, adicionou-se $30 \mu \mathrm{L}$ de óleo mineral para evitar a evaporação das amostras.

\section{Ciclos de amplificação}

As amplificações foram efetuadas em termociclador (PTC-100 MJ Resear$\mathrm{ch}$ ), programado para uma etapa de desnaturação inicial a $95^{\circ} \mathrm{C}$ por $3 \mathrm{~min}$, seguindo-se 45 ciclos a $95^{\circ} \mathrm{C}$ por $1 \mathrm{~min}, 35^{\circ} \mathrm{C}$ por $1 \mathrm{~min}$ e $72^{\circ} \mathrm{C}$ por $1 \mathrm{~min}$. Ao final, realizou-se uma etapa de extensão a $72^{\circ} \mathrm{C}$ por 5 min. 


\section{Análise por eletroforese dos fragmentos de DNA gerados por RAPD}

Os produtos de amplificação originários das reações de RAPD foram separados em gel de agarose 1,5\% (Sigma) submerso em tampão TBE 1X (Tris-borato $90 \mathrm{mM}$ e EDTA $1 \mathrm{mM}$, Sigma) durante $3 \mathrm{~h}$ a $160 \mathrm{~V}$. Ao término da corrida, os géis foram corados por 30 min em uma solução corante contendo brometo de etídio (5 $\mu \mathrm{g} . \mathrm{mL}^{-1}$ ), descorados por $30 \mathrm{~min}$ em água destilada e fotografados sob luz ultravioleta no comprimento de onda de $300 \mathrm{~nm}$. A documentação fotográfica foi feita usando-se o sistema EagleEye II still video system (Stratagene).

Em todos os géis, marcadores de massa molecular (100 bp Ladder - Invitrogen) foram usados para a determinação da massa molecular dos fragmentos amplificados pela técnica de RAPD.

\section{Análise dos dados}

As fotos das amplificações realizadas com os oligonucleotídios selecionados foram utilizadas para a análise do polimorfismo entre os isolados analisados. Os fragmentos de DNA presentes nos géis foram considerados como marcadores RAPD. Logo após, foi gerada uma matriz de similaridade, levando-se em consideração as relações entre indivíduos iniciadores e massas moleculares dos fragmentos obtidos com um dado oligonucleotídio. Utilizou-se o valor 1 para a presença de um marcador e 0 para a ausência. No caso de dúvida, o número 9 foi usado como padrão.

A seguir, a planilha obtida foi submetida a um programa de análise estatística multivariada para a determinação das distâncias genéticas entre os indivíduos. A matriz de similaridade foi obtida por meio do coeficiente de Jaccard (SNEATH; SOKAL, 1973) e que, por meio da análise por UPGMA - Unweighted Pair-Group Method Analysis - (SWOFFORD; OLSEN, 1990), produziu um dendrograma que evidenciou o agrupamento dos isolados, utilizando-se o programa NTSYS (Numerical Taxonomy and Multivariate Analysis System) versão 2. 02 pc (RHOLF, 1993). 
Os valores obtidos e tabelados em uma planilha foram submetidos à análise de variância molecular (AMOVA) para a determinação estatística das possíveis origens das variabilidades encontradas nas amostras pela aplicação de algoritmos específicos pelo programa Arlequin version 2000 (SCHNEIDER, 2000).

\section{Resultados e discussão}

Identificação morfológica dos isolados de fungos

Observou-se que dos 23 isolados utilizados nesse estudo, 14 foram identificados como sendo do gênero Aspergillus (60,87\%), 7 relacionados ao gênero Penicillium (30,43\%) e 1 correspondente ao gênero Fusarium (4,35\%). Além disso, 1 isolado $(4,35 \%)$ não foi identificado pelos critérios morfológicos.

A partir dessas informações, os isolados foram submetidos à análise molecular para a confirmação das identificações pelos critérios morfológicos.

\section{Metodologia de obtenção de ácidos nucléicos de fungos}

As adaptações do protocolo de extração de DNA, baseado em Azevedo . (2003), produziram DNA em quantidade e qualidade suficientes para se aplicar a técnica de RAPD, levando-se em consideração algumas modificações como a não utilização do nitrogênio líquido e outras soluções como o tampão de espermidina

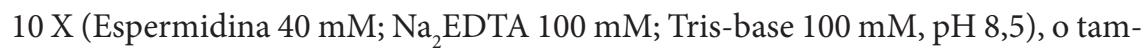
pão TNE (Tris-HCl 10 mM, pH 8,0; EDTA 1 mM, pH 8,0; NaCl 100 mM) e triton $\mathrm{X}-10010 \%(\mathrm{p} / \mathrm{v})$. A partir dessas adaptações, obteve-se em torno de $1 \mu \mathrm{g} \cdot \mathrm{mL}^{-1} \mathrm{de}$ DNA por amostra, ou seja, reduziu-se o custo operacional garantindo-se a viabilidade da metodologia quanto à sua função. 


\section{Oligonucleotídios de RAPD}

Dentre os oligonucleotídios testados, dez deles apresentaram sucesso na amplificação dos fragmentos de DNA (OPA-03, OPA-04, OPA-10, OPA-11, OPA13, OPR-02, OPR-04, OPR-06, OPR-09 e OPR-10), enquanto dez não produziram perfis que pudessem ser considerados para as análises moleculares (OPA-12, OPA15, OPA-17, OPA-18, OPA-20, OPR-01, OPR-05, OPR-08, OPR-13 e OPR-14).

Os dez oligonucleotídios de RAPD selecionados produziram um total de 136 fragmentos de amplificação com uma média de 13,6 \pm 3,13 marcadores por iniciador (Tabela 2).

Tabela 2: Número total de fragmentos produzidos por 10 iniciadores de RAPD utilizados na análise dos isolados pertencentes a três gêneros de fungos. D. P. Desvio padrão

\begin{tabular}{cc}
\hline Iniciador de RAPD & $\begin{array}{c}\text { Fragmentos gerados por } \\
\text { iniciador }\end{array}$ \\
\hline OPA-03 & 16 \\
OPA-04 & 16 \\
OPA-10 & 14 \\
OPA-11 & 16 \\
\hline OPA-13 & 16 \\
\hline OPR-02 & 9 \\
\hline OPR-04 & 16 \\
\hline OPR-06 & 8 \\
\hline OPR-09 & 14 \\
\hline OPR-10 & 11 \\
\hline Total & 136 \\
Média & 13,6 \\
\hline D. P. & 3,13 \\
\hline
\end{tabular}

Observou-se que os oligonucleotídios OPA-03, OPA-04, OPA-11, OPA-13 e OPR-04 produziram o maior número de fragmentos de DNA por iniciador, enquanto os oligonucleotídios OPR-06 e OPR-02 produziram o menor número de produtos de amplificação por RAPD. 
Os 10 iniciadores de RAPD selecionados produziram perfis eletroforéticos para a identificação dos isolados relacionados aos gêneros Aspergillus e Penicillium (Tabela 3).

Tabela 3: Tipos de fragmentos gerados por 10 iniciadores de RAPD utilizados na identificação molecular e análise filogenética de Aspergillus e Penicillium.

\begin{tabular}{|c|c|c|c|c|c|c|c|c|c|c|c|}
\hline \multirow{3}{*}{ Fragmentos de DNA } & \multicolumn{10}{|c|}{ Iniciador de RAPD } & \multirow{3}{*}{ Total } \\
\hline & \multicolumn{5}{|c|}{ OPA } & \multicolumn{5}{|c|}{ OPR } & \\
\hline & 03 & 04 & 10 & 11 & 13 & 02 & 04 & 06 & 09 & 10 & \\
\hline Específicos para Aspergillus & 3 & 4 & 0 & 3 & 3 & 0 & 0 & 0 & 0 & 2 & 15 \\
\hline Específicos para Penicillium & 2 & 4 & 0 & 0 & 3 & 0 & 1 & 0 & 5 & 0 & 15 \\
\hline $\begin{array}{r}\text { Isomórficos } \\
\text { Aspergillus e Penicillium }\end{array}$ & 0 & 2 & 11 & 0 & 2 & 0 & 0 & 0 & 0 & 0 & 15 \\
\hline $\begin{array}{l}\text { Polimórficos } \\
\text { Aspergillus e Penicillium }\end{array}$ & 11 & 6 & 3 & 13 & 8 & 9 & 15 & 8 & 9 & 9 & 91 \\
\hline Total & 16 & 16 & 14 & 16 & 16 & 9 & 16 & 8 & 14 & 11 & 136 \\
\hline
\end{tabular}

Os oligonucleotídios OPA-11 e OPR-10 produziram fragmentos de RAPD específicos para Aspergillus (3,7\%), enquanto os iniciadores OPR-04 e OPR-09 geraram produtos de RAPD específicos para a identificação de Penicillium (4,4\%).

Observou-se também que os iniciadores OPA-04, OPA-10 e OPA-02 geraram fragmentos de DNA comuns a ambos os gêneros (11,0\%). Os iniciadores da série OPR não geraram qualquer fragmento isomórfico relacionados aos fungos em questão.

Quanto à obtenção de fragmentos de RAPD polimórficos, os oligonucleotídios OPR-04 e OPA-11 geraram o maior número de produtos de amplificação correspondendo a $20,6 \%$.

Em seguida, analisou-se a porcentagem de cada oligonucleotídio na obtenção de perfis eletroforéticos relacionados para cada gênero de isolado, incluindo aquele não identificado (Tabela 4 ). 
Tabela 4: Porcentagem de fragmentos de DNA (\%) gerados por oligonucleotídios de RAPD na identificação de isolados de fungos de interesse médico.

\begin{tabular}{|c|c|c|c|c|c|c|c|c|c|c|c|}
\hline \multirow{3}{*}{ Gênero } & \multicolumn{10}{|c|}{ Fragmentos de DNA gerados por oligonucleotídio de } & \multirow{3}{*}{$\begin{array}{c}\text { Total } \\
(\%)\end{array}$} \\
\hline & \multicolumn{5}{|c|}{ OPA } & \multicolumn{5}{|c|}{ OPR } & \\
\hline & 03 & 04 & 10 & 11 & 13 & 02 & 04 & 06 & 09 & 10 & \\
\hline Aspergillus & 14,4 & 13,3 & 10,4 & 12,9 & 7,7 & 17,7 & 4,9 & 8,4 & 6,2 & 4,2 & 100 \\
\hline Penicillium & 10,3 & 12,4 & 9,8 & 13,5 & 9,8 & 17,7 & 4,4 & 12,4 & 7,2 & 2,6 & 100 \\
\hline Fusarium & 5,9 & 11,8 & 7,4 & 11,8 & 11,8 & 20,6 & 7,4 & 5,9 & 13,2 & 4,4 & 100 \\
\hline $\begin{array}{c}\text { Não } \\
\text { identificado }\end{array}$ & 9,7 & 19,4 & 12,9 & 29 & 22,6 & 0 & 0 & 6,5 & 0 & 0 & 100 \\
\hline
\end{tabular}

Observou-se que o iniciador OPR-02 foi responsável por 17,7\% da geração de fragmentos de RAPD nos isolados dos gêneros Aspergillus e Penicillium, como também para Fusarium, com 20,6\%. Para o isolado não identificado observou-se que o iniciador OPA-11 correspondeu a $29 \%$ na obtenção dos fragmentos de RAPD.

Contudo, o iniciador OPR-10 gerou as menores porcentagens de produção de fragmentos de RAPD para a análise dos isolados de Fusarium (4,4\%), Aspergillus (4,2\%) e Penicillium (2,6\%).

Com relação ao isolado não identificado, observou-se que os oligonucleotídios OPR-02, OPR-04, OPR-09 e OPR-10 não produziram fragmentos de RAPD que permitissem a sua identificação. Com relação à série $\mathrm{R}$, apenas o oligonucleotídio OPR-06 gerou fragmentos de amplificação (6,5\%).

\section{Perfis eletroforéticos de RAPD}

O padrão de fragmentos de DNA obtido para cada um dos isolados analisados permitiu identificar marcadores moleculares específicos para os gêneros de acordo com o oligonucleotídio utilizado (Figura 1). 


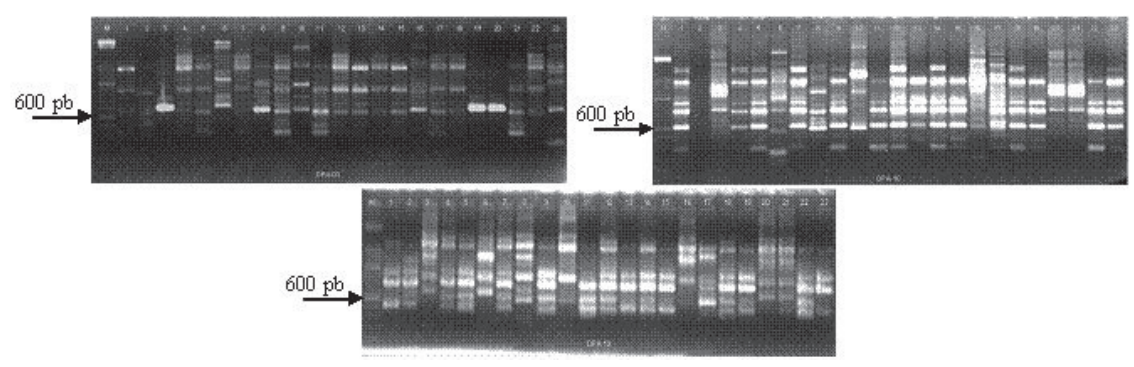

Figura 1: Perfis eletroforéticos de isolados de fungos pertencentes aos gêneros Aspergillus, Penicillium e Fusarium, produzidos pela utilização de vários oligonucleotídios de RAPD. A letra $\mathrm{M}$ indica o marcador de massa molecular $100 \mathrm{pb}$ ladder. Os números de acordo com a Tabela I indicam: 1, 4, 5, 7, 9, 10, 12, 13, 14, 15, 16, 18, 19, 23 e 24, isolados do gênero Aspergillus; 3, 6, 8, 17, 20, 21 e 22, isolados de Penicillium; 11, isolado pertencente ao gênero Fusarium; 2, isolado de fungo não identificado.

O iniciador OPA-03 produziu fragmentos isomórficos de 650 pb, 950 pb e 1500 pb nos isolados de Aspergillus. Para os isolados de Penicillium, observou-se um fragmento comum de aproximadamente $500 \mathrm{pb}$.

Para os isolados de Aspergillus o iniciador OPA-10 produziu fragmentos comuns de 650 pb, 850 pb, 1000 pb e 1550 pb. Entretanto, o isolado 17, no gel de agarose, produziu um perfil diferente dos demais. Em Penicillium foram observados genótipos diferenciados. Os isolados 3, 20 e 21 apresentaram o mesmo padrão de fragmentos de RAPD enquanto os isolados 6, 8 e 16 apresentaram perfis distintos entre si, reforçando a presença de genótipos diferentes entre os isolados desse gênero.

O iniciador OPA-13 produziu um padrão de fragmentos de RAPD comum à maioria dos isolados de Aspergillus, exceto para o isolado 17. Em Penicillium, observou-se perfil similar de marcadores para os isolados 3, 20 e 21. Contudo, para os isolados 6, 8 e 16 os padrões apresentaram variação, sugerindo a presença de genótipos diferentes.

O isolado não identificado apresentou padrão de fragmentos similar aos genótipos de Aspergillus. Entretanto, a diferença foi relacionada à presença de fragmentos que não foram encontrados em nenhum isolado de Aspergillus.

As reações de amplificação de RAPD apresentaram reprodutibilidade nas triplicatas para cada iniciador. Segundo Cruz e Milach (1998), a reprodutibilidade está 
fortemente associada à qualidade do DNA e à padronização das condições de reação. O número de fragmentos amplificados normalmente é, em função da espécie, do oligonucleotídio e das condições da amplificação. Em reações de RAPD, normalmente são amplificados fragmentos entre $500 \mathrm{pb}$ a 2500 pb (FERREIRA; GRATTAPAGLIA, 1998). No presente trabalho, a maior parte dos marcadores obtidos ficou no intervalo de $200 \mathrm{pb}$ a $1300 \mathrm{pb}$.

Vários estudos demonstraram a viabilidade do emprego, ainda da técnica de RAPD, na identificação de fungos de interesse médico. Linhagens de A. fumigatus isoladas de 4 pacientes hospitalares foram discriminadas pelo emprego da técnica de RAPD utilizando o iniciador R108 (SEMIGHINI; DELMAS; PARK, 2001). Essa metodologia também foi aplicada na diferenciação de F. sporotrichioides e Fusarium langsethiae (WILSON; SIMPSON; CHANDLER., 2004). Cardoso, Queiroz e Pereira (2007) testaram 78 iniciadores de RAPD e 8 apresentaram diferenças no padrão de fragmentos, com 54\% de polimorfismo. A partir desses estudos, foram obtidos 2 fragmentos de 600 pb e 594 pb para a identificação de P. expansum e Penicillium griseoroseum. Nesse trabalho, com o emprego de apenas 10 iniciadores de RAPD obteve-se $67 \%$ de polimorfismo entre os isolados dos dois gêneros de fungos.

Os resultados desse trabalho produziram 15 potenciais fragmentos de DNA capazes de discriminar, de forma rápida, os isolados de Aspergillus e Penicillium por RAPD. Os iniciadores OPA-03, OPA-04 e OPA-13 podem ser simultaneamente usados para a discriminação desses dois gêneros de fungos. Confirmou-se pela estratégia adotada que o isolado F123 pertence a outro gênero de fungo, uma vez que o iniciador OPA-11 foi o responsável pela maior parte do polimorfismo para esse isolado, diferentemente do oligonucleotídio OPR-02 que foi o maior responsável pela geração de variabilidade entre os demais isolados de fungos. Em Penicillium, provavelmente, existem genótipos diferentes. Os iniciadores OPA-04, OPA-10 e OPA-13 mostram o potencial em gerar fragmentos de DNA para a discriminação desses genótipos. Por essa estratégia, ainda se questionou a identificação do isolado P002 como sendo pertencente ao gênero Fusarium.

Esses procedimentos moleculares simples podem ser usados na triagem de pacientes acometidos por alguma infecção fúngica, reduzindo os custos operacionais 
de identificação do patógeno e aumentando a eficiência do procedimento de identificação, não necessitando o desenvolvimento de sistemas de PCR multiplex.

\section{Dendrograma}

Os dados obtidos por 10 iniciadores de RAPD selecionados foram utilizados para gerar um dendrograma, que demonstrou a formação de vários agrupamentos entre os isolados de fungos analisados (Figura 2).

Os isolados de Aspergillus apresentaram 46\% de similaridade em relação aos de Penicillium. Dentro do agrupamento de Aspergillus foram encontrados dois clados (A1 e C1) com 53\% de similaridade. No clado A1 foram encontrados 6 isolados. Dentro do clado C1 ocorreu uma subdivisão (B1) apresentando 60\% de similaridade. No clado B1 foram encontrados cinco isolados e no $\mathrm{C} 1$ outros quatro isolados. Entre os isolados de Aspergillus a similaridade genética variou de 53\% a 76\%.

Os isolados de Penicillium formaram dois clados (A2 e B2) com 53\% de similaridade. No clado A2 foram encontradas duas subdivisões com $55 \%$ de similaridade e no clado B2 foi agrupado o isolado P002, inicialmente definido como Fusarium. A similaridade entre os isolados de Penicillium variou de $53 \%$ a $70 \%$. Os dados moleculares indicam a necessidade de reclassificação do isolado P002, uma vez que este isolado apresenta 70\% de similaridade com o isolado F0062 de Penicillium. Esses dados sugerem que os isolados P002 e F0062 sejam um mesmo tipo de genótipo de Penicillium.

O isolado F123 apresentou 25\% de similaridade em relação aos demais isolados utilizados nesse estudo indicando, provavelmente, que este isolado pertença a outro gênero de fungo.

Associou-se o perfil de fragmentos de RAPD gerado pelo oligonucleotídio OPA-04 ao dendrograma, observando-se três grupos distintos (A1, B1 e C1) para Aspergillus. Para Penicillium, foram obtidos dois grupos distintos (A2 e B2), sugerindo genótipos diferentes entre os isolados desse gênero de fungo. Além disso, o isola- 
do P002, identificado como Fusarium, apresentou um perfil de fragmentos de DNA semelhante ao isolado F0062 de Aspergillus. Essa informação indica que uma nova avaliação deverá ser feita no que concerne à identificação do isolado de Fusarium.

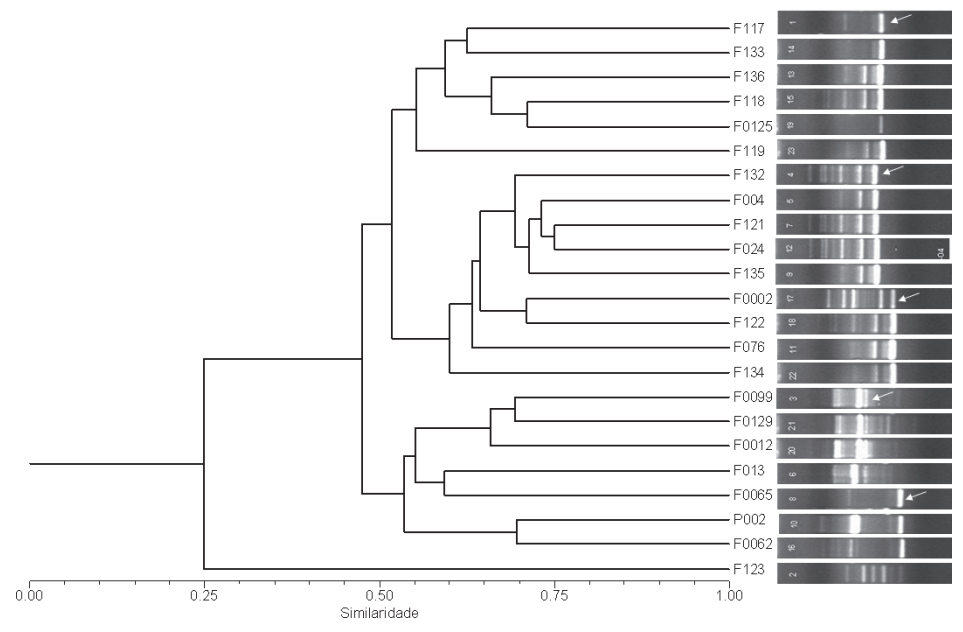

Figura 2: Dendrograma e padrão de fragmentos obtidos por 10 iniciadores de RAPD a partir de 23 isolados de fungos. Os códigos indicam: F117, F132, F004, F121, F120, F135, F076, F024, F136, F133, F118, F002, F122, F134 e F119, isolados de Aspergillus; F0099, F013, F0065, F0062, F0125 e F0012, isolados de Penicillium; P002, Fusarium; F123, isolado de fungo não identificado. A seta branca indica o fragmento de RAPD característico de cada grupo.

O isolado F123 apresentou um perfil de fragmentos diferente dos demais isolados, sugerindo que o mesmo pertence a outro isolado de fungo.

Esses dados reforçam que a reação de amplificação por RAPD é um método sensível e eficiente na identificação de isolados muito semelhantes, que apresentem alto coeficiente de similaridade.

\section{Análise de Variância Molecular (AMOVA)}

Analisando-se a variabilidade de todos os isolados observou-se que 26,43\% eram provenientes de variações entre os gêneros de fungos e 73,57\% provenientes de variações que ocorriam dentro de cada gênero de fungo (FST $=0,26430)$. A partir da 
análise comparativa entre os isolados de Aspergillus e Penicillium, observou-se que $23,44 \%$ da variabilidade era devido a variações entre os gêneros e 76,56\%, de variações entre os isolados de um mesmo gênero (FST = 0, 23437). Comparando-se o isolado não identificado com os isolados dos gêneros Aspergillus e Penicillium, obteve-se que, $22,50 \%$ da variação era devido a variações entre os grupos e que 77,50\% dela devia-se a variações relacionadas a cada grupo analisado (FST $=0,22497)$. A comparação entre o isolado previamente identificado como Fusarium e os demais isolados de Aspergillus indicou que 43,07\% da variação foram provenientes de diferenças entre os grupos e 56,93\% relacionadas a variações dentro de cada gênero analisado (FST = $0,43070)$.

Portanto, a maior fonte de variabilidade genética deveu-se a variações entre os isolados de cada gênero de fungo, ou seja, isolados fenotipicamente semelhantes de uma mesma espécie apresentam variações genotípicas que estão relacionadas aos seus respectivos gêneros.

Entretanto, para o isolado previamente identificado como sendo pertencente ao gênero Fusarium, há a necessidade de revisão taxonômica, uma vez que este se agrupou no mesmo clado dos isolados de Aspergillus e a análise de AMOVA sugere que as diferenças genéticas não são tão acentuadas para se considerar um gênero diferente de Aspergillus. Provavelmente o isolado P002 seja um genótipo diferente de Aspergillus. Essa evidência é reforçada pelo dendrograma, visto que aquele isolado agrupou-se com o isolado F0062 identificado previamente como Aspergillus. Condições do meio de cultura, tais como, $\mathrm{pH}$, distribuição de fontes de carbono e nitrogênio, suplemento vitamínico e temperatura exercem efeitos pronunciados na fisiologia e morfologia dos fungos, o que poderia explicar o possível equívoco na identificação do isolado P002.

A partir dessa situação, a técnica de RAPD associada às análises de variância molecular reforça a praticidade e a importante contribuição dos marcadores moleculares na identificação e reclassificação de isolados de fungos. Essa abordagem é particularmente importante quando há dúvidas a respeito das características morfológicas de um isolado que possa interferir na sua correta classificação, podendo interferir decisivamente na abordagem clínica. 
Rath (2002) usaram marcadores RAPD para a análise de 21 isolados de Aspergillus usutus divididos em 11 linhagens de referência e 10 linhagens isoladas a partir de amostras de pacientes em ambientes hospitalares. As reações de RAPD discriminaram-se entre todas as linhagens de referência. Além disso, a comparação entre as linhagens de hospital mostrou padrões de RAPD idênticos com algumas amostras isoladas de pacientes. Essa mesma estratégia foi usada por Baddley (2003) em testes clínicos para o monitoramento e detecção de isolados de $A$. terreus resistentes à anfotericina em pacientes atendidos em um hospital universitário.

Portanto, os resultados gerados pelos marcadores RAPD confirmaram a ocorrência de uma considerável variabilidade genética entre os isolados de fungos estudados, fornecendo ainda dados moleculares complementares mais precisos, visando à identificação de fungos. Isso é particularmente importante, quando a descrição morfológica não fornece dados completos para a identificação desses isolados, como o ocorrido para o isolado P002, confirmando mais uma vez que os marcadores RAPD podem ser utilizados para diagnóstico molecular de isolados de gêneros de fungos de importância médica.

A partir do estabelecimento de uma estratégia rápida e em pequena escala para a obtenção de DNA com quantidade e qualidade para as análises por marcadores RAPD, fragmentos específicos a um dado gênero/espécie de fungo obtido neste trabalho, poderão ser utilizados no desenvolvimento de oligonucleotídios de PCR para a identificação específica de isolados de Aspergillus e Penicillium ocorrendo no ambiente médico-hospitalar.

\section{Molecular identification of fungi strains of medical interest by RAPD markers}

Abstract

Aspergillus and Penicillium are microrganisms able to produce severe clinical complications, mainly in imunossupressed patients. The molecular analysis is an important strategy to quickly and precisely identify these pathogenic agents. The objecti- 
ve of this work was to describe specific RAPD molecular patterns to identify isolates of Aspergillus and Penicillium which produce diseases of medical relevance. The morphological analyses revealed 14 isolates were Aspergillus, 7 were Penicillium, one isolate was Fusarium and only one isolate was unknown. The RAPD analyses using ten primers produced DNA fragments specific to each genera. The dendrogram showed groups of isolates inside each fungus genera and these groups were identified by specific DNA molecular markers. Besides, these groups of isolates showed high similarity coefficient. These data revealed potential DNA fragments able to be converted to specific DNA primers to identify one specific fungus isolate occurring in the hospital environment.

Keywords: DNA analyses. Aspergillus. Penicillium. Polymorphism.

\section{Referências}

AZEVEDO, O. M.; FELIPE, S. S. M.; BRIGIDO, M. M. Técnicas básicas em biologia molecular. Brasília: Universidade de Brasília, 2003.

BERED, F; BARBOS, N. J. F; CARVALHO, F. I. F. Marcadores moleculares e sua aplicação no melhoramento genético de plantas. Ciência Rural, Santa Maria, RS, v. 27, p. 13-520, 1997. doi:10.1590/S0103-84781997000300026.

BADDLEY, J. W. Epidemiology of Aspergillus terreus at a university hospital. Journal of Clinical Microbiology, Washington, v. 41, p. 5525-5529, 2003. doi:10.1128/ JCM.41.12.5525-5529.2003

CARDOSO, P. G.; QUEIROZ, M. V.; PEREIRA, O. L. Morphological and molecular differentiation of the pectinase producing fungi Penicillium expansum and Penicillium griseoroseum. Brazilian Journal of Microbiology, São Paulo, v. 38, p. 71-77, 2007. doi:10.1590/S1517-83822007000100015.

CRUZ, R. P.; MILACH, S. C. K. Marcadores moleculares em plantas. Porto Alegre: UFRGS, 1998.

DIAZ-GUERRA, M. T.; MELLADO, E.; CUENCA-ESTRELLA, M. Genetic similarity among one Aspergillus flavus strain isolated from a patient whounderwent heart surgery and two environmental strains obtained from the operation room. Journal of Clinical Microbiology, Washington, v. 38, p. 2419-2422, 2000. 
FERREIRA, M. E.; GRATTAPAGLIA, D. Introdução ao uso de marcadores moleculares em análises genéticas. Brasília: EMBRAPA-CENARGEN, 1998.

HUE, F. X.; HUERRE, M.; ROUFFAULT, M. A. Specific detection of Fusarium species in blood and tissues by a PCR technique. Journal of Clinical Microbiology, Washington, v. 37, p. 2434-2438, 1999.

LARSEN, T. O.; FRYDENVANG, K.; FRISVAD, J. C. UV- guided screening for benzodiazepine producing species in Penicillium. Biochemistry and Systematic Ecology, San Francisco, v. 28, p. 881-886, 2000. doi:10.1016/S0305-1978(99)00126-X

LEENDERS, A. et al. Molecular epidemiology of an apparent outbreak of invasive aspergillosis en a hematology ward. Journal of Clinical Microbiology, Washington, v. 34, p. 345-351, 1996.

LOURENÇO, A.; DURIGON, E. L.; ZANOTTO, P. Genetic diversity of environmental Aspergillus flavus strains in the state of São Paulo, Brazil by random amplified polymorphic DNA. Memórias do Instituto Oswaldo Cruz, Rio de Janeiro, v. 102, p. 687-692, 2007. doi:10.1590/S0074-02762007005000102.

MELLADO, E.; DIAZ-GUERRA, T. M.; CUENCA-ESTRELLA. Characterization of a possible nosocomial Aspergillosis outbreak. Clinical Microbriology and Infection, New York, v. 6, p. 543-548, 2000. doi:10.1046/j.1469-0691.2000.00154.x.

NORITOMI, D. T. et al. Multiple brain abscesses due to Penicillium spp infection. Revista Instituto de Medicina tropical de São Paulo, São Paulo, v. 47, p. 167-170, 2005. doi: 10.1590/S0036-46652005000300010

OLIVEIRA, C. V.; COSTA, S. L. J. Análise de restrição de DNA ribossomal amplificado (ANDRA) pode diferenciar Fusarium solani f. sp. phaseoli de F. solani f. sp. I. Fitopatologia Brasileira, Brasília, v. 27, p. 631-634, 2002. doi:10.1590/S010041582002000600013.

PITT, J. I. The current role of Aspergillus and Penicillium in human and animal health. Journal of Medical and Veterinary Mycology, [S.1.], v. 3, p. 17-32, 1994. doi:10.1080/02681219480000701.

RATH, P, M; ANSORG, R. Value of environmental sampling and molecular typing of aspergilli to assess nosocomial sources of aspergillosis. Journal of Hospital Infection, San Francisco, v. 37, p. 47-53, 1997. doi:10.1016/S0195-6701(97)90072-4. 
RHOLF, F. J. NTSYSpc: Numerical taxonomy and multivariate analysis system, version 2. 0. Exeter Software Setauket, New York, 1993.

RHAME, F. S. Prevention of nosocomial aspergillosis. Journal of Hospital Infection, San Francisco, v. 18, p. 466-472, 1991. doi:10.1016/0195-6701(91)90058-G.

SCHNEIDER, S.; ROESSLI, D.; EXCOFFIER, L. Arlequin Version 2000: a software for populations genetics data analysis. Switzerland: Genetics and biometry laboratory of University of Geneva, 2000.

SEMIGHINI, C. P.; DELMAS, G.; PARK, S. New restriction fragment length polymorphism (RFLP) markers for Aspergillus fumigatus. FEMS Immunology and Medical Microbiology, Baltimore, v. 31, p. 15-19, 2001. doi:10.1111/j.1574-695X.2001. tb01580.x.

SNEATH, P. A.; SOKAL, R. R. Numerical taxonomy. San Francisco: Freeman, 1973.

SWOFFORD, D. L. PAUP. Phylogenetic analysis using parsimony (and other methods): version 4. 0b4a. Sunderland, MA: Sinauer Associates, 1998.

SYMOENS, F; BOUCHARA, J-P.; HEINEMANN, S. Molecular typing of Aspergillus terreus isolates by random amplification of polymorphic DNA. Journal of Hospital Infection, San Francisco, v. 44, p. 273-280, 2000. doi:10.1053/jhin.1999.0707.

THRANE, U. Grouping Fusarium section discolor isolates by statistical analysis of quantitative high performance liquid chromatographyc data on secondary metabolite production. Journal of Microbiological Methods, San Francisco, v. 12, p. 23-39, 1990. doi:10.1016/0167-7012(90)90004-P.

WILLIAMS, J. G. K.; KUBELIK, A. R.; LIVAK, K. J. DNA polymorphisms amplified by arbitrary primers are useful as genetic markers. Nucleic Acids Research, Oxford, v. 18, p. 6531-6535, 1990. doi:10.1093/nar/18.22.6531.

WILSON, A.; SIMPSON, D; CHANDLER, E. Development of PCR assays for the detection and differentiation of Fusarium sporotrichioides and Fusarium langsethiae. FEMS Microbiological Letters, Baltimore, v. 233, p. 69-76, 2004. doi:10.1016/j. femsle.2004.01.040. 